\title{
KNOWLEDGE AND ATTITUDE REGARDING TUBERCULOSIS TREATMENT AMONG DOT PROVIDERS OF RNTCP REGISTERED PATIENTS IN KOTTAYAM DISTRICT, KERALA
}

\author{
Chintha Sujatha1, Ajith Raveendran², Sreejith Lalitha Krishnankutty ${ }^{3}$ \\ 1Assistant Professor, Department of Community Medicine, Government Medical College, Thiruvananthapuram. \\ ${ }^{2}$ Assistant Surgeon, General Hospital, Kottayam. \\ ${ }^{3}$ Assistant Surgeon, General Hospital, Kottayam.
}

ABSTRACT

\section{BACKGROUND}

DOT Provider's knowledge, attitudes and perceptions about Tuberculosis play an important role in their ability to care for individuals with Tuberculosis and is a major determinant of successful completion of TB treatment.

Objective- To assess Knowledge and Attitude regarding Tuberculosis treatment among DOT Providers of RNTCP registered patients in Kottayam district, Kerala.

\section{MATERIALS AND METHODS}

A cross-sectional study was done among 248 DOT providers of RNTCP registered patients in Kottayam district. DOT Providers were interviewed by the investigator using a structured interview schedule. For assessing knowledge regarding Tuberculosis, a validated questionnaire was used and knowledge score calculated. Data entry and analysis was done using statistical software SPSSv16.

\section{RESULTS}

Mean knowledge score out of 15 was 9.19 (SD- 4.741). Health staff had a significantly higher knowledge score than Community DOT providers $(\mathrm{P}<0.001)$. DOT providers who received training in RNTCP had a significantly greater knowledge score $(\mathrm{P}<0.001)$.

\section{CONCLUSION}

After assessing the knowledge and attitude of DOT providers, gaps were found. There is a need to impart training and reorientation courses to update the knowledge of DOT providers regarding the TB disease, its diagnosis, treatment and followup of patients.

\section{KEYWORDS}

Knowledge, Attitude, DOT Providers, Tuberculosis.

HOW TO CITE THIS ARTICLE: Sujatha C, Raveendran A, Krishnankutty SL. Knowledge and attitude regarding tuberculosis treatment among DOT providers of RNTCP registered patients in Kottayam district, Kerala. J. Evolution Med. Dent. Sci. 2017;6(90): 6264-6267, DOI: $10.14260 /$ jemds/2017/1362

\section{BACKGROUND}

Tuberculosis (TB) is a disease that has severely affected communities and nations since times immemorial. It continues to be a leading cause of death even today, despite the availability of effective diagnostic and therapeutic tools. RNTCP has developed National Strategic Plan to be implemented during 2012-2017, the national 12th Five Year plan period. The Vision is "TB-free India" and Goal is Universal Access to quality TB diagnosis \& treatment for all pulmonary \& extra pulmonary TB patients including drug resistant and HIV associated TB. The key focus of the programme is to reduce default rates and to prevent the emergence of drug resistance. The key intervention planned is strengthening and improving the quality of basic DOTS services. ${ }^{1}$

'Financial or Other Competing Interest': None.

Submission 08-10-2017, Peer Review 02-11-2017,

Acceptance 09-11-2017, Published 20-11-2017.

Corresponding Author:

Dr. Chintha Sujatha,

Assistant Professor,

Department of Community Medicine,

Government Medical College,

Thiruvananthapuram.

E-mail: sujathachintha@gmail.com

DOI: $10.14260 /$ jemds $/ 2017 / 1362$

\section{(c) $(1)$}

The DOT strategy has been considered one of the most cost-effective health interventions by the World Bank. ${ }^{2}$ While DOT is central to the success of tuberculosis control programmes, it is not easy to implement. Several types of providers are carrying out treatment observation in various situations like health workers, Anganwadi workers, teachers, private practitioners and other community volunteers. Studies show that there is wide variation in the effectiveness of services rendered by different types of DOT providers. A variety of factors such as socioeconomic and cultural background, training, practice settings, attitudes, etc. influence the performance of DOT providers which in turn influence the treatment outcome. ${ }^{3}$ DOT Providers' knowledge, attitudes and perceptions about Tuberculosis play an important role in their ability to care for individuals with Tuberculosis. ${ }^{4}$ Only limited studies are done in Kerala on Knowledge and attitude of DOT providers regarding Tuberculosis treatment which in turn is an important determinant of treatment outcome.

\section{Objective}

To assess Knowledge and Attitude regarding Tuberculosis treatment among DOT Providers of RNTCP registered patients in Kottayam district, Kerala.

\section{MATERIALS AND METHODS}

A cross-sectional study was done among 248 DOT providers of RNTCP registered patients in Kottayam district. List of DOT 
Providers of patients undergoing continuation phase of treatment were obtained from the five Tuberculosis units of the district. All those willing to participate in the study were included. DOT Providers were interviewed by the investigator using a structured interview schedule. For assessing knowledge regarding Tuberculosis a validated questionnaire was used and knowledge score calculated. Data entry and analysis was done using statistical software SPSSv16. Continuous variables were summarised as means and standard deviation. Independent sample $t$ test was used to test statistical significance. Categorical variables were summarised as proportions. Non-parametric test, MannWhitney $U$ test used for testing significance for knowledge score. Ethical clearance was obtained from Institutional Ethical Committee and written informed consent was obtained from all participants.

\section{RESULTS}

Out of the 248 DOT Providers studied, 22 (8.9\%) were male and $226(91.1 \%)$ were female. Mean age of DOT providers was 41.63 years and Standard deviation was 8.077 years with a Range of $19-64$ years. Majority $(62.9 \%)$ of the DOT providers belong to the age group 30-45 years. Proportion of DOT providers belonging to Middle class was 77.5\%. Only 2 of the DOT providers belong to Upper class, both of them were treating doctors and $22.2 \%$ of DOT providers were from lower class. Majority of the DOT providers have completed their PDC/Intermediate/post high school diploma (57.3\%) and $34.3 \%$ of DOT providers have completed High school. Only $7.3 \%$ of DOT providers have higher Educational status like graduation/postgraduation/profession/honours. ASHAs were the major category of DOT providers followed by Govt. staff nurses and Anganwadi workers. Field staff who previously were the major category has now reduced to a meagre $1.6 \%$ as they now entrust ASHAs with the job. The four-field staff included three TBHVs and one JPHN. Others constitute $6 \%$ which included neighbours, local leaders, volunteers of charitable institutions and one co-student.

\begin{tabular}{|c|c|c|}
\hline Category & Frequency & Percentage \\
\hline Field staff & 4 & 1.6 \\
\hline Govt. Pharmacist & 33 & 13.3 \\
\hline Govt. staff nurse & 58 & 23.4 \\
\hline Anganwadi worker & 49 & 19.8 \\
\hline ASHA & 78 & 31.5 \\
\hline Private hospital staff & 11 & 4.4 \\
\hline Others & 15 & 6.0 \\
\hline Total & $\mathbf{2 4 8}$ & $\mathbf{1 0 0}$ \\
\hline \multicolumn{2}{|c|}{ Table 1. DOT Provider Categories } \\
\hline
\end{tabular}

\begin{tabular}{|c|c|c|}
\hline Grouped Category & Frequency & Percentage \\
\hline Health staff & 106 & 42.7 \\
\hline Community DOT providers & 142 & 57.3 \\
\hline Total & 248 & 100.0 \\
\hline \multicolumn{3}{|c|}{$\begin{array}{l}\text { Table 2. DOT Provider Categories Grouped into } \\
\text { Health Staff and Community DOT Providers }\end{array}$} \\
\hline
\end{tabular}

For the purpose of further analysis DOT provider categories were grouped into two major categories, Health staff and Community DOT providers. Community DOT providers which included Anganwadi workers, ASHAs and 'others' constituted the major (57.3\%) category. About 200 (80.6\%) of the DPs were trained in RNTCP which include mostly half- day training in RNTCP. Most of the trainings were conducted at PHC level and staff from DTO led the trainings. Among the 48 untrained DOT providers, 26 were ASHAs and 13 belonged to the 'others' category. $86.7 \%$ of DOT Providers among the 'others' category were untrained and 33.3\% among ASHAs were untrained. All of the DOT Providers who were private hospital staff and Govt. field staff were trained.

\section{Knowledge of DOT Providers Regarding RNTCP}

15 questions were asked and a score of 1 was given to each correct answer. Mean knowledge score was 9.19, SD 4.741, median 10, minimum score recorded was 0 and maximum 15 .

\begin{tabular}{|c|c|c|}
\hline Score & Frequency & Percentage \\
\hline$\geq 10$ & 130 & 52.4 \\
\hline $5-10$ & 64 & 25.8 \\
\hline$<5$ & 54 & 21.8 \\
\hline Total & $\mathbf{2 4 8}$ & $\mathbf{1 0 0 . 0}$ \\
\hline \multicolumn{2}{|c|}{ Table 3. Knowledge Score of DOT Providers } \\
\hline
\end{tabular}

\begin{tabular}{|c|c|c|c|c|}
\hline \multirow{2}{*}{$\begin{array}{c}\text { DOT Provider } \\
\text { Category }\end{array}$} & \multicolumn{3}{|c|}{ Knowledge Score } & \multirow{2}{*}{ Total } \\
\cline { 2 - 4 } Field staff & $\mathbf{2 1 0}$ & $\mathbf{5 - 1 0}$ & $<\mathbf{5}$ & \\
\hline Govt. & $100.0 \%$ & 0 & 0 & 4 \\
pharmacists & $93.9 \%$ & $6.1 \%$ & $0 \%$ & $100.0 \%$ \\
\hline Govt. staff & 48 & 6 & 4 & 53 \\
nurses & $82.8 \%$ & $10.3 \%$ & $6.9 \%$ & $100.0 \%$ \\
\hline Anganwadi & 13 & 24 & 12 & 49 \\
worker & $26.5 \%$ & $49.0 \%$ & $24.5 \%$ & $100.0 \%$ \\
\hline \multirow{2}{*}{ ASHA } & 23 & 25 & 30 & 78 \\
& $29.5 \%$ & $32.1 \%$ & $38.5 \%$ & $100.0 \%$ \\
\hline Private & 11 & 0 & 0 & 11 \\
hospital staff & $100.0 \%$ & $0 \%$ & $0 \%$ & $100.0 \%$ \\
\hline \multirow{2}{*}{ Others } & 0 & 7 & 8 & 15 \\
& $0 \%$ & $46.7 \%$ & $53.3 \%$ & $100.0 \%$ \\
\hline \multirow{2}{*}{ Total } & $\mathbf{1 3 0}$ & $\mathbf{6 4}$ & $\mathbf{5 4}$ & $\mathbf{2 4 8}$ \\
& $\mathbf{5 2 . 4 \%}$ & $\mathbf{2 5 . 8 \%}$ & $\mathbf{2 1 . 8 \%}$ & $\mathbf{1 0 0 . 0 \%}$ \\
\hline
\end{tabular}

Table 4. DOT Provider Category and Knowledge Score

Majority of field staff (100\%), private hospital staff (100\%), pharmacists $(93.9 \%)$ and staff nurses $(82.8 \%)$ had score more than or equal to 10 . But $6.9 \%$ of staff nurses had a score less than five. Among ASHAs $29.5 \%$ had a score more than or equal to 10 . But $38.5 \%$ of ASHAs and $53.3 \%$ of 'others had a score below five.

\begin{tabular}{|c|c|c|}
\hline $\begin{array}{c}\text { DOT Provider } \\
\text { Category }\end{array}$ & Number & $\begin{array}{c}\text { Median Knowledge Score } \\
\text { (Interquartile Range) }\end{array}$ \\
\hline Health staff & 106 & $14(12-15)$ \\
\hline $\begin{array}{c}\text { Community DOT } \\
\text { provider }\end{array}$ & 142 & $7(3-10)$ \\
\hline Total & $\mathbf{2 4 8}$ & $\mathbf{1 0}(5-14)$ \\
\hline Table 5. DOT Provider Grouped Category and Knowledge \\
Score \\
\hline
\end{tabular}

Mann-Whitney U score $=1.644 \mathrm{E} 3, \mathrm{p}$ value $<0.001$

Health staff had a significantly higher knowledge score than Community DOT providers. 


\begin{tabular}{|c|c|c|}
\hline Training Status & Number & $\begin{array}{c}\text { Median Knowledge Score } \\
\text { (Interquartile Range) }\end{array}$ \\
\hline Trained & 200 & $12(7-14)$ \\
\hline Untrained & 48 & $2.5(0-6)$ \\
\hline Total & $\mathbf{2 4 8}$ & $\mathbf{1 0}(5-14)$ \\
\hline Table 6. Training Status and Knowledge Score \\
\hline
\end{tabular}

Mann-Whitney U score $=781, \mathrm{p}<0.001$

DOT providers who received training in RNTCP had a significantly greater knowledge score.

\begin{tabular}{|c|c|c|c|c|}
\hline No. & Knowledge & $\begin{array}{c}\text { Correct } \\
(\mathbf{\%})\end{array}$ & $\begin{array}{c}\text { Incorrect } \\
\mathbf{( \% )}\end{array}$ & $\begin{array}{c}\text { Total } \\
\mathbf{( \% )}\end{array}$ \\
\hline 1 & Examination of contacts & 52.8 & 47.2 & 100 \\
\hline 2 & TB suspect & 65.3 & 34.7 & 100 \\
\hline 3 & Cause of TB & 63.3 & 36.7 & 100 \\
\hline 4 & RNTCP & 50.8 & 49.2 & 100 \\
\hline 5 & Duration of treatment & 69.8 & 30.2 & 100 \\
\hline 6 & $\begin{array}{c}\text { Retrieval period in } \\
\text { intensive phase }\end{array}$ & 56.5 & 43.5 & 100 \\
\hline 7 & $\begin{array}{c}\text { Retrieval period in } \\
\text { continuation phase }\end{array}$ & 16.1 & 83.9 & 100 \\
\hline 8 & Spread of TB & 90.7 & 9.3 & 100 \\
\hline 9 & Mainstay of diagnosis & 82.7 & 17.3 & 100 \\
\hline 10 & Reddish colour of urine & 58.9 & 41.1 & 100 \\
\hline 11 & Jaundice & 64.1 & 35.9 & 100 \\
\hline 12 & Symptoms of TB & 85.1 & 14.9 & 100 \\
\hline 13 & Types of TB & 66.1 & 33.9 & 100 \\
\hline 14 & HIV-TB link & 52 & 48 & 100 \\
\hline 15 & MDR- TB & 43.5 & 56.5 & 100 \\
\hline Table 7. Knowledge of DOT Providers & & \\
\hline
\end{tabular}

Table 7. Knowledge of DOT Providers Regarding RNTCP

\begin{tabular}{|c|c|c|}
\hline No. & Question Seeking Attitude & $\begin{array}{c}\text { Positive } \\
\text { Response (\%) }\end{array}$ \\
\hline 1 & Willing to be a DOT provider again & 89.9 \\
\hline 2 & Motivate others to be DOT providers & 44.8 \\
\hline 3 & Satisfied with incentive & 43.5 \\
\hline 4 & $\begin{array}{c}\text { Feels that being a DOT provider is } \\
\text { beneficial }\end{array}$ & 53.2 \\
\hline 5 & Work or daily routine is not affected & 80.6 \\
\hline 6 & No fears of contracting the disease & 58.9 \\
\hline 7 & $\begin{array}{c}\text { Do not feel that there is social stigma } \\
\text { for TB }\end{array}$ & 19.4 \\
\hline 8 & Prefer DOT to self-administration & 79 \\
\hline 9 & $\begin{array}{c}\text { Adherence to treatment, greatest } \\
\text { advantage of DOT }\end{array}$ & 75 \\
\hline 10 & Prefer Govt. health institutions & 96 \\
\hline \multicolumn{2}{|c|}{ Table 8. Attitude of DOT Providers } \\
\hline \multicolumn{2}{|c|}{} \\
\hline
\end{tabular}

\section{DISCUSSION}

Majority of field staff (100\%), private hospital staff (100\%), pharmacists (93.9\%) and staff nurses (82.8\%) had knowledge score more than or equal to 10 . But $6.9 \%$ of staff nurses had a score less than five which is a matter of concern. Among ASHAs, $29.5 \%$ had a score more than or equal to 10 which is an encouraging finding. But $38.5 \%$ of ASHAs and $53.3 \%$ of others had a score below five. DOT providers who received training in RNTCP had a significantly greater knowledge score. Priority should be given for strengthening training activities especially among community DOT Providers. Training should be imparted to each DOT provider before they start administering DOTS. Reorientation courses should be organised periodically.

Top scoring questions were about spread of tuberculosis, symptoms and mainstay of diagnosis. Questions with poor response were retrieval period in continuation phase, MDRTB, TB-HIV link and what is RNTCP.

Kaur A et al found out that all of the DOT providers were aware that pulmonary tuberculosis is a communicable disease. 45 (90\%) DOT providers said that pulmonary tuberculosis is the most common form of the disease. All DOT providers knew that TB spread by droplets and cough with expectoration is the symptom of tuberculosis. Majority of the DOT providers i.e. $78 \%$ said that tuberculosis is suspected if the patient had any of the symptoms like, evening rise of temperature, blood in sputum, chest pain, weight loss or family history of tuberculosis. Only 32 (64\%) DOT providers knew about full terminology of DOTS i.e. Directly Observed Treatment Short-course \& 36\% did not know the correct terminology. ${ }^{5}$

Regarding attitude towards Tuberculosis treatment, almost all DOT providers prefer DOTS to self-administration and believe that adherence to treatment is the greatest advantage with DOTS. Majority (96\%) of them prefer government health institutions and $89.9 \%$ of them are willing to be DOT providers again. But majority of them are not satisfied with the incentive and only $53.2 \%$ believe that being a DOT provider is beneficial to them. Many of them fear contracting the disease and most of them feel that social stigma is associated with the disease. Kaur A et al observed that $40 \%$ of DOT providers had fear of contracting the disease.

Health care worker's knowledge, attitudes and perceptions about Tuberculosis play an important role in their ability to diagnose and care for individuals with Tuberculosis. A variety of factors, such as training, cultural and ethnic background, practice settings, preferred sources of information and learning styles influence them. The successful completion of TB treatment is influenced greatly by 'how' care is delivered to individuals. It is paramount that Health care worker supporting clients with TB have positive attitudes. ${ }^{4}$ Knowledge about new and retreatment cases should be given to them. Constant monitoring and supervision is required by trained staff in Tuberculosis Unit. 5

\section{CONCLUSION}

DOT Providers play a vital role in the grass root level implementation of RNTCP. After assessing the knowledge and attitude of DOT providers, gaps were found. There is a need to impart training to DOT providers before they start administering DOTS Therapy. Reorientation courses should be organised periodically to update the knowledge of DOT providers regarding the TB disease, its diagnosis, treatment and followup of patients.

\section{REFERENCES}

[1] Central TB Division, Director General of Health Services; Ministry of Health and Family Welfare, New Delhi. TB India 2016 Revised National TB Control programme Annual status Report, March 2016.

[2] The World Bank, Investing in health: World Development Report 1993, New York, NY: Oxford University press, 1993. 
[3] WHO Report. Global Tuberculosis control, WHO 2016.

[4] Dimitrova B, Balabanova D, Atun R, et al. Health services provider's perceptions of barriers to tuberculosis care in Russia. Health Policy Plan 2006;21(4):265-74.
[5] Kaur A, Balgir RS, Kaur P, et al. Knowledge and attitude of DOT providers in tuberculosis unit of Patiala. Directory of Open Access J 2012;11(2):3. 